\title{
Improving Male Attendance in Antenatal Clinics through Reduction in Delivery Fees as Incentives for their Pregnant Spouses: a Case Study in Rivers State, Nigeria
}

\author{
Article by Dr. Kenny C. Ewulum \\ MBA, Texila American University, member of the Project management Institute (PMI) in USA, \\ Nigeria \\ E-mail:drkennyewulum@gmail.com
}

\begin{abstract}
Background: Despite increases in reproductive health interventions that target male involvement in maternal health, there are still evidences to show that male spouses for some reasons do not support their spouses during antenatal care sessions. This would otherwise serve as an avenue for health education and ensure males can support their spouses through the antennal period and in child birth. The Objective: The purpose of the study was to ascertain levels of participation of male spouses in antenatal clinics and the effect of reducing cost of delivery to improving male antenatal attendance. Materials and Methods: This descriptive cross-sectional study was undertaken in Port Harcourt and Obio-akpor Local Government Areas in Rivers State, Nigeria. Semi-structured questionnaires were used to collect information from pregnant women, male spouses, healthcare workers and Medical directors. Results: Notably following interviews was that both male and pregnant women alike were aligned to the thinking that women were generally more likely to be concerned about antenatal care than men. Secondly reducing the amount for delivery during child birth by health care providers drastically increased the number of men attending antenatal clinics with their spouses. Conclusion: The study has shown that incentives for men during antenatal care can serve as a strategy for improving maternal outcomes during child birth. Notably is that there is need for continued strategies to ensure male involvement in antenatal care to improve health education especially in low resource settings.
\end{abstract}

Keywords: Improving male attendance in antenatal clinics

\section{Introduction}

Despite long standing education on the importance of male involvement in maternal health, there has barely been a rise in the number of males attending antenatal care clinics. Globally, maternal deaths contribute to more than half a million of deaths yearly, and of these, $99 \%$ occur in developing countries [1, 2]. The World Health Organization (WHO) in 2013 records that 286,000 of maternal deaths are accounted for by developing countries and are as a result of preventable complications $[2,3]$. Notably also, the primary causes of maternal death are the result of three delays; delay seeking care, delay reaching health care facilities and delay at an institution in providing appropriate care [4]. Since the spouses of theses pregnant women could play a role at these levels of care, male involvement is thus critical. Delays that occur can often be the result of women seeking support from the head of the household, often men. This is especially the case when the situation involves the need for funds [2]. Involving men would allow them to support their partners to prepare for the delivery and seek out emergency care if necessary. The importance of male involvement in reproductive health programs was emphasized at the International Conference on Population Development held in Cairo in 1994. Over the years, there has been a proportionate increase in reproductive health initiatives that target both men and women in a bid to fulfill the $5^{\text {th }}$ Millennium Development Goal which supports universal access to reproductive health. Male spouses' role cannot be ruled out when it pertains to pregnancy and childbirth. 
DOI: $10.21522 /$ TIJMG.2015.03.02.Art020

ISSN: $2520-310 \mathrm{X}$

Although acknowledged out rightly certain benefits of male involvement, there have been bottlenecks in creating a space for and engaging them in maternal health. Cultural norms have also posed as constraints for instance, some communities perceive the role of men only as in leadership and some men probably would see attending antenatal clinics with their pregnant spouses as demeaning to their roles as heads of the family [5]. Although there may be advantages to having men involved in maternal health, it is not clear if women on their part would find this involvement acceptable and how it could be negotiated as in the communities, this was previously considered as the domain of women. Notably also is that men who were knowledgeable and obtained health education were more likely to accompany their spouses for ANC visit [6].

Notably also, Men in patriarchal societies of developing countries are often identified as decision makers in all aspects of day-to-day life including pregnancy, antenatal care and child birth. The question still remains, how do we get men to attend antenatal clinics as an avenue for their health education to ensure they support their pregnant spouses through pregnancy and child birth?

This study aims to;

1. Explore factors that limit male involvement in antenatal care

2. Assess potential effect of reducing delivery costs to increasing male attendance in antenatal clinics

\section{Methods}

This study took place in Rivers state, a multicultural and multitribal state with over 28 language dialects. Located in the southern part of Nigeria Rivers is one of the 36 states of the country and the sixth-most populous state in the country with a population of 5,198,716. There are also 23 Local Government areas (LGAs) across the state. Its capital and largest city is Port harcourt and is economically significant as the center of Nigeria's oil industry.

There are over 500 health facilities in Rivers state with 2 tertiary health institutions. Some of these are Private for profit and others state and federal government owned.

Table 1. Facility distribution by ownership and level of care

\begin{tabular}{|l|l|l|l|}
\hline \multirow{2}{*}{ OWNERSHIP } & \multicolumn{2}{|l|}{ FACILITY TYPE } & \multirow{2}{*}{ TOTAL } \\
\cline { 2 - 3 } & $\begin{array}{l}\text { PRIMARY } \\
\text { LEVEL }\end{array}$ & SECONDARY LEVEL & \\
\hline Private & 86 & 118 \\
\hline Private for profit & 32 & 20 & 203 \\
\hline Public & 1 & 6 \\
\hline State government & 183 & 5 & 327 \\
\hline $\begin{array}{l}\text { Federal } \\
\text { government }\end{array}$ & 5 & 107 & \\
\hline Overall total & 220 &
\end{tabular}

Assessment done shows that about 92 health facilities do not provide antenatal care services. Port harcourt and Obio-akpor Local government areas share same boundaries and are the largest areas in the state with more of the urban settlements. Despite this, patronage of hospitals is still poor some persons attributing this to the associated antenatal and delivery costs and others to cultural norms which endear women to deliver in Traditional birth homes. These local government areas were chosen because most of the health care facilities in the state are concentrated here. There would likely be a perception of the greater majority of the health facilities in the state.

This study was a cross-sectional study which incorporated the use of a simple questionnaire. Focus group discussions (FGDs) was also conducted for pregnant women in groups who attended antenatal care sessions. 
The questionnaire was piloted on five pregnant women with some adjustments to the words to ensure clarity in interpretation of the information. The questionnaires were distributed during antenatal sessions and all the questionnaires were returned anonymously. Questions mainly centered on decision making and the role of the partners in pregnancy choice, antenatal care and childbirth. 3 health facilities were randomly selected to ascertain the perception of both pregnant women, their male spouses as well as healthcare workers to explore factors that limit male involvement in antenatal care.

Mount Hermon hospital was chosen as the healthcare facility to assess potential effect of reducing delivery costs to increasing male attendance in antenatal clinics. This is a secondary health facility located in Obio-akpor LGA and one of the supported health facility by USAID for the implementation of the Evidence to Action - The Nigerian Private Sector PMTCT Plus project in Rivers state, a project on integrating Reproductive Health services to reducing maternal to child transmission of HIV (PMTCT). This was chosen for the pilot study based on standards of documentation of medical records, as well as successes on previous projects. The hospital management staff was involved through the process of offering discounts for spouse's delivery.

Data collection was carried out in 2 phases and sources; at the beginning of a 6- month period (November 2015) from the medical records department, and from the pregnant women and male partners during antenatal sessions.

Table 2. Total number of respondents in the state

\begin{tabular}{|c|c|c|}
\hline S/no & Nature of Respondents & Number \\
\hline 1 & Pregnant women & 40 \\
\hline 2 & Male partners & 8 \\
\hline 3 & Healthcare workers & 12 \\
\hline \multicolumn{2}{|l|}{ Total } & 60 \\
\hline
\end{tabular}

\section{Results}

A. Focus Group discussion and interviews

Of the respondents, majority stated that decisions on number of children and when to get pregnant was not a collective choice by both partners. It was mostly by chance. Most women in the community do not negotiate sex and pregnancy. Of the 8 male partners interviewed, 5 suggested it was a collective decision.

Table 3. Response to perception on joint decision making on number and when to get pregnant

\begin{tabular}{|l|l|l|l|l|}
\hline S/no & Nature of Respondents & Yes & No & N/A \\
\hline 1 & Pregnant women & 7 & 29 & 4 \\
\hline 2 & Male partners & 5 & 3 & 0 \\
\hline 3 & Healthcare workers & 2 & 4 & 6 \\
\hline
\end{tabular}

Table 4. Identified barriers to male attendance in antenatal clinics

\begin{tabular}{|c|c|}
\hline s/no & Reason given for non-attendance at ANC \\
\hline 1 & Lack of information on the importance of attendance \\
\hline 2 & Perceived non-inclusiveness of men during antenatal sessions \\
\hline 3. & $\begin{array}{c}\text { Perceived socio-cultural norms for example shame in community if } \\
\text { men are involved in pregnancy care and domestic work }\end{array}$ \\
\hline 4. & Perceived trap into testing for HIV \\
\hline
\end{tabular}

B. At the beginning of the study, only 1 male partner was seen during antenatal session compared to 12 pregnant women in the clinic. With the introduction of the incentives, out of the 18 pregnant women 
DOI: $10.21522 /$ TIJMG.2015.03.02.Art020

ISSN: $2520-310 \mathrm{X}$

during antenatal in May 2016 (6-month period) 7 male partners accompanied their spouses during the antenatal sessions.

Table 5. Number of male attendees in antenatal clinic by November 2015

\begin{tabular}{|l|l|l|}
\hline Health Facility & Pregnant women attending ANC & Accompanied by spouse \\
\hline Hospital 1 & 10 & 2 \\
\hline Hospital 2 & 18 & 1 \\
\hline Mount Hermon Hospital & 12 & 1 \\
\hline
\end{tabular}

Table 6. Number of male attendees in antenatal clinic by November 2015

\begin{tabular}{|l|l|l|}
\hline Health Facility & Pregnant women attending ANC & Accompanied by spouse \\
\hline Hospital 1 & 8 & 2 \\
\hline Hospital 2 & 23 & 1 \\
\hline Mount Hermon Hospital & 18 & 7 \\
\hline
\end{tabular}

\section{Discussions}

This study reveals that men especially in low resource settings could actually attend antenatal clinics if acceptable incentives were given. $30 \%$ or $50 \%$ discounts could be given for certain percentage attendance with one's spouse during the antenatal period. Certain delivery packages could also be discounted for. This could go a long way to encourage other males who shy away from these sessions to participate knowing full well that fellow men are also at such clinics.

Majority of the women still believe the men determine the number of children they could have and when this occurs.

Participants had proposed the following recommendations during the focused group discussions;

- That there is need to increase community health education for male participation in antenatal care.

- Antenatal clinics and health workers should make the sessions more inclusive of male roles.

- That there should be direct communication between the healthcare providers and the male spouses since they tend to take this more seriously that when communicated by their pregnant spouses.

Limitations; one limitation of this study was that this study was conducted in an area with low income earning individuals which may undermine its validity and its ability to reveal the truth so there could be bias on this relationship in high income earning areas.

Further research; More knowledge is needed to establish whether programming in reproductive health and maternal health would target incentives to male spouses rather than directly to the pregnant women. This area deserves further research, perhaps through more in-depth qualitative method.

\section{Conclusion}

This study contributes to the strategies in improving male involvement in antenatal care. Male partners in low resource settings could be offered certain forms of incentives during the spouse's antenatal period to encourage participation in care. Discounts could be given for complete or partial attendance through the entire antenatal period. This participation would serve as an avenue for health education particularly to create community awareness and improve the perception of male participation in antenatal clinics. Male participation would attract further male participation. 


\section{Figures}

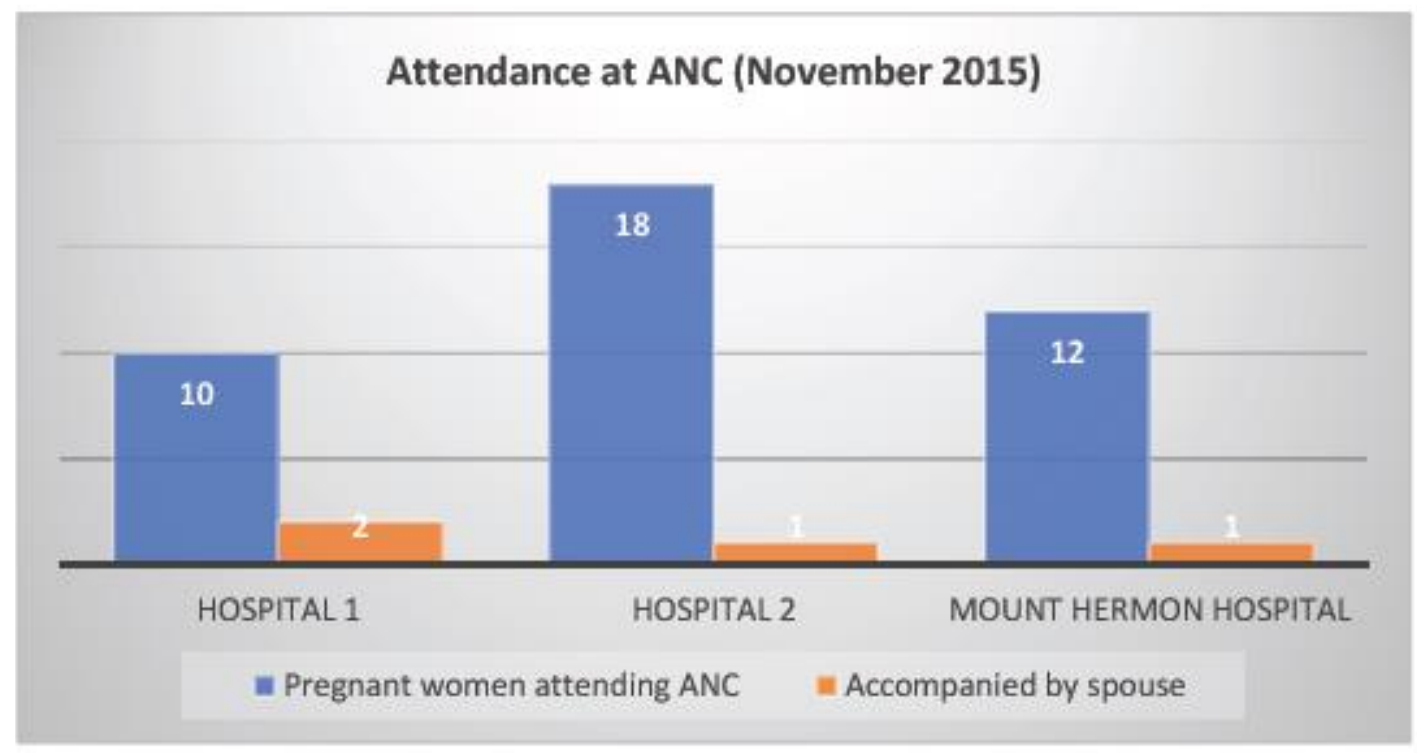

Figure 1. Antenatal attendance at onset of intervention

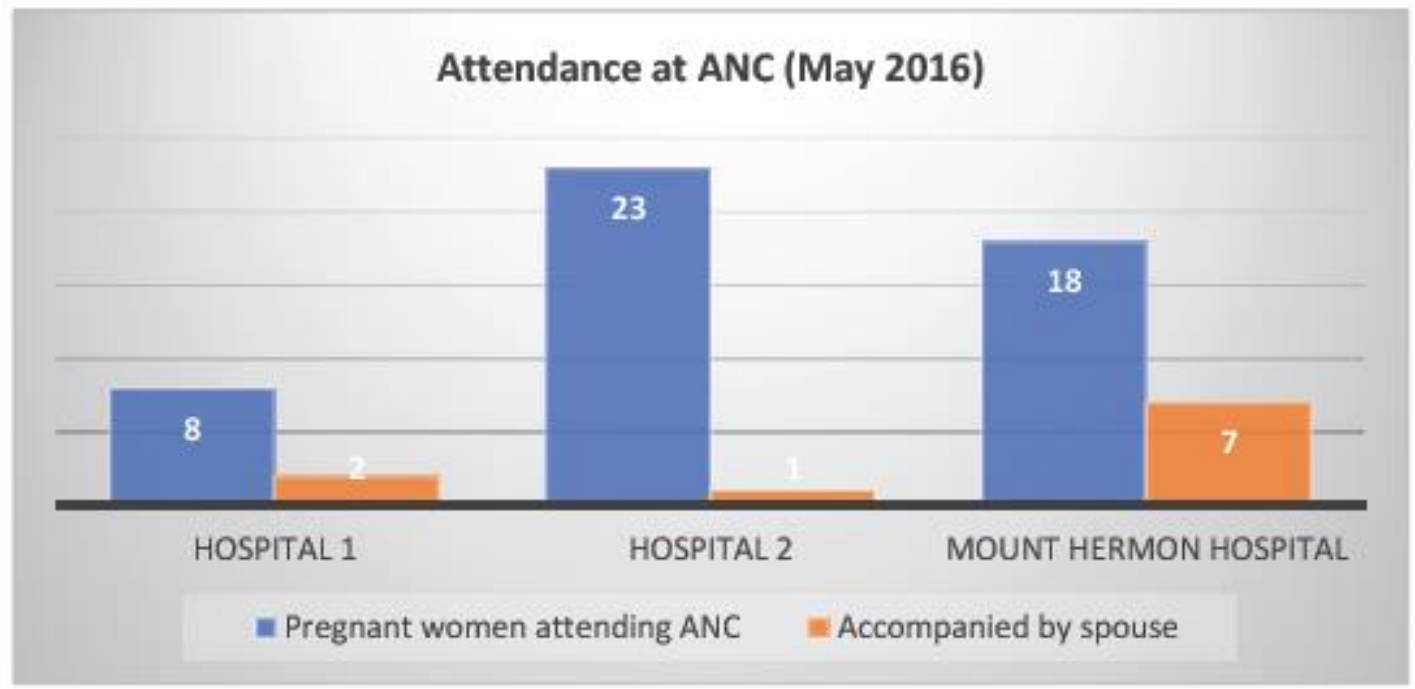

Figure 2. Antenatal clinic attendance 6-month after intervention

\section{Acknowledgement}

Author wish to acknowledge all those who agreed to participate in this study

\section{References}

[1].Carter M. Husbands and maternal health matters in rural Guatemala: wives' reports on their spouses' involvement in pregnancy and birth. Soc Sci Med. 2002; 55(3):437-50. PMID: 12144151

[2].Dudgeon MR, Inhorn MC. Men's influences on women's reproductive health: medical anthropological perspectives. Soc Sci Med. 2004; 59(7):1379-95. PMID 51246168

[3].JHPIEGO. Maternal and Neonatal health $(\mathrm{MNH})$ program, birth preparedness and complication readiness: A matrix of shared responsibilities. Maternal and Neonatal Health. 2001. pp. 23-31. 
DOI: $10.21522 /$ TIJMG.2015.03.02.Art020

ISSN: $2520-310 \mathrm{X}$

[4].McPherson RA, Khadka N, Moore JM, Sharma M. Are birth-preparedness programmes effective? Results from a field trial in Siraha district, Nepal. Journal of Health Population and Nutrition. 2006; 24(4):479-88. [PMC free article] [PubMed]

[5].WHO, UNICEF, UNFPA, the World Bank, the United Nations Population Division. Trends in Maternal Mortality: 1990 to 2013. Geneva, Switzerland: World Health Organization; 2014.

[6].World Health Organization. Maternal death surveillance and response: Technical guidance information for action to prevent maternal death. Geneva, Switzerland: World Health Organization; 2013.

[7].World Health Organization. Women and Health: Today's Evidence, Tomorrow's Agenda. Geneva, Switzerland: World Health Organization; 2009. 